\title{
Identifikasi Mineral Pasir Tiga Warna Pantai Puntaru Kabupaten Alor-NTT
}

\author{
Martasiana Karbeka, Herianus Manimoy, Bertho A. Abolasing
}

${ }^{a}$ Kimia FMIPA, Universitas Tribuana Kalabahi, Kalabahi, 85813, Indonesia

INFO ARTIKEL

\begin{tabular}{l}
\hline Diterima 31 Maret 2021 \\
Disetujui 29 April 2021 \\
\\
\hline Key word: \\
Three-colored sand \\
Silica \\
Magnetite \\
Sulfur oxide \\
XRF \\
XRD \\
\\
\hline Kata kunci: \\
Pasir tiga warna \\
Silica \\
Magnetit \\
Sulphur oksida \\
XRF \\
XRD
\end{tabular}

\begin{abstract}
A B STRAK
Pantai Puntaru terkenal dengan pasir tiga warna yang bercampur menjadi satu yakni pasir berwarna coklat kemerahan, hitam dan putih. Penelitian tentang komposisi mineral pada pasir tiga belu pernah dilakukan sehingga pemanfaatan pasir tiga warna masih dilakukan secara tradisional. Penelitian ini bertujuan untuk diperoleh informasi kandungan silika dan komposisi mineral lainnya pada pasir tiga warna Pantai Puntaru sebagai data awal dalam pengembangan lebih lanjut. Proses preparasi pasir tiga warna dilakukan dengan metode milling/penghancuran sampel pasir kemudian diayak dan dilakukan pencucian dengan $\mathrm{H}_{2} \mathrm{O}$. Tahapan karakterisasi silika pada pasir tiga warna dilakukan dengan menggunakan $X$-ray fluorescence (XRF), X-ray powder diffraction (XRD) dan Fourier-transform infrared (FTIR). Hasil analisis menunjukkan bahwa persentase Si paling dominan yaitu 45,28\% diikuti oleh $\mathrm{Fe}$ 25,94\% dan unsur-unsur minor lainnya. Hasil XRD menunjukkan bahwa pada pasir tiga warna terkandung silika kristalin $\left(\mathrm{SiO}_{2}\right)$ fasa quartz yang teridentifiksai pada puncak utama dengan $2 \theta$ pada daerah $24,34^{\circ}$. Warna hitam pada pasir dipengaruhi oleh kandungan $\mathrm{Fe}$ $25,94 \%$ dengan oksida logam hematit $\left(\mathrm{Fe}_{2} \mathrm{O}_{3}\right) \quad 15,80 \%$ dan coklat kemerahan dipengaruhi oleh keberadaan sulfur (3,25\%) dalam bentuk mineral $\mathrm{SO}_{3} 4,32 \%$.
\end{abstract}

\begin{abstract}
A B S T R A C T
Puntaru beach is famous for its three-colored sand that is mixed into one of the reddish-brown, black and white sand. Research on the mineral composition of the tricolor sand has been conducted so that the use of three-colored sand is still done traditionally. This study aims to obtain information on the silica content and other mineral compositions of the three-colored sand of Puntaru beach as initial data for further development. The three-color sand preparation process is carried out by the method of milling crushing sand samples then sieving and washing with $\mathrm{H}_{2} \mathrm{O}$. Stages of characterization of silica in three-colored sand were carried out using X-ray fluorescence (XRF), X-ray powder diffraction (XRD), and Fourier-transform infrared (FTIR). The analysis showed that the percentage of $S i$ was the most dominant $45.28 \%$, followed by Fe 25.94\% and other minor elements. XRD results show that the three-colored sand contains quartz mineral $\left(\mathrm{SiO}_{2}\right)$ identified at the main peak with $2 \theta$ within the $24.34^{\circ}$ area. The black color of the sand is influenced by Fe content of $25.94 \%$ with hematite metal oxide $\left(\mathrm{Fe}_{2} \mathrm{O}_{3}\right) 15.80 \%$ and reddish-brown influenced by the presence of sulfur $(3.25 \%)$ in the form of mineral $\mathrm{SO}_{3} 4.32 \%$.
\end{abstract}

mineral pasir pantai sangat bervariasi dan bergantung pada keadaan lingkungan suatu wilayah. Batuan yang ada di gunung

\section{Pendahuluan}

Pasir pantai merupakan sumber mineral yang paling banyak ditemukan. Kemurnian 
mengalami proses pelapukan akibat gaya-gaya luar yang bekerja dan yang terutama pengaruh air dan suhu sehingga terurai menjadi bagianbagian yang kecil (fragmen) yang disuplai ke laut oleh aliran sungai. Ketika fragmen itu sampai di laut, selanjutnya akan dipindahkan ke sepanjang pantai yang disebabkan oleh gelombang arus membentuk tumpukan pasir di pantai. Proses tersebut mempengaruhi variasi komposisi mineral pasir pantai di berbagai daerah. Komposisi unsur pada pasir pantai terdapat dalam bentuk oksida logam. Oksida logam dengan persentase komposisi yang tinggi tergolong dalam unsur mayor sedangkan unsur/mineral dengan persentase kecil merupakan mineral-mineral minor [1-3]. Pasir pantai terdiri atas beberapa warna yakni pasir pantai warna putih, pasir pantai warna hitam dan lainnya. Warna pasir yang terlihat dipengaruhi oleh kandungan unsur/mineral dan persentasenya. Unsur yang dominan berkontribusi sebagai pemberi warna pada pasir pantai diperkirakan derajat kemurniannyan [4]. Sedangkan mineral minor kurang berkontribusi dalam pemberi warna dan termasuk dalam kategori mineral pengganggu [5-7].

Pasir Pantai Puntaru terdiri atas tiga warna yakni coklat kemerahan, hitam dan putih. Pasir berwarna hitam merupakan pasir besi dengan unsur dominan adalah besi (magnetit, $\mathrm{Fe}_{3} \mathrm{O}_{4}$ ). Pasir putih merupakan pasir silika tinggi $\left(\mathrm{SiO}_{2}\right)$ dan dapat juga merupakan pasir dengan kalsium tinggi dalam bentuk kalsium karbonat $\left(\mathrm{CaCO}_{3}\right)$ [1,4,5,8]. Warna pasir coklat kemerahan dimungkinkan adanya kandungan oksida sulfur pada pasir tersebut $\left(\mathrm{SO}_{3}\right)$ dikarenakan lokasi penelitian berada dekat dengan Gunung Sirung yang merupakan gurung berapi aktif. Pasir besi telah dimanfaatkan secara luas sebagai serta bahan dasar untuk industri magnet permanen, adsorben, sebagai bahan dasar tinta kering, dan pigmen warna. Pasir silika telah banyak dimanfaatkan sebagai bahan utama pembuatan gelas dan kaca serta bahan baku pembuatan sel surya. Silika dan kalsium karbonat telah dikembangkan sebagai bahan nanokomposit untuk material keramik dan aplikasi di dunia industri yang berkaitan dengan produk farmasi, katalis dan pengembangan adsorben yang bersifat magnet [9-12]. Oleh karena itu, penelitian pada pasir tiga warna Pantai Puntaru akan memberikan kajian mineral yang terkandung di dalamnya. Kajian mineral pasir tiga warna dianalisis dengan pengujian $X$-ray Fluorescence (XRF) untuk mengetahui elemen yang terkandung, pengujian X-ray Diffraction (XRD) untuk mengetahui kandungan fasa secara kualitatif dan Fourier Transform Infrared (FTIR) dalam menentukan gugus fungsi.

\section{Bahan dan Metode}

Bahan yang digunakan adalah sampel pasir tiga warna dari Pantai Puntaru dan aquades. Peralatan yang digunakan adalah mortar dan ayakan. Peralatan instrument untuk analisis yaitu XRF PANalytical Epsilon 1, XRD Diffraktometer PANalytical-Empyrean, FTIR Shimadzu. Prosedur kerja mengikuti prosedur [1] dengan sedikit modifikasi. Tahap awal yang dilakukan yakni preparasi sampel pasir tiga warna. Sampal pasir tiga warna dicuci dengan akuades hingga bersih dan dikeringkan pada suhu $70-80{ }^{\circ} \mathrm{C}$ selama 2 jam. Pasir tiga warna digerus dan diayak kemudian hasil ayakan pasir tiga warna dicuci hingga bersih. Selanjutnya dikeringkan pada suhu $70-80{ }^{\circ} \mathrm{C}$ selama 2 jam lalu dilakukan karakterisasi lanjutan. Pada tahap akhir dilakukan karakterisasi sampel pasir tiga warna menggunakan peralatan intrumen seperti XRF untuk mengetahui kandungan unsur penyusunnnya, XRD untuk mengetahui jenis fasa yang dominan dan FTIR untuk mengetahui gugus fungsi.

\section{Hasil dan Pembahasan}

Analisis X-Ray Fluorescence (XRF)

Kandungan oksida logam pada pasir tiga warna Pantai Puntaru dilakukan dengan instrumen XRF. Hasil analisis yang dihasilkan berupa data kualitatif jenis unsur dan persentase komposisi unsur penyusun pasir tiga warna. Hasil uji pasir tiga warna dengan instrumen XRF menunjukkan bahwa unsur yang dominan adalah Si 45,28\% dan Fe 25,94\%, dan unsur lainnya sebagai unsur-unsur minor yang berpengaruh terhadap pembentukan warna pada pasir tiga warna. Untuk data lengkap kandungan oksida logam pasit tiga warna dari Pantai Puntaru Kabupaten Alor 
dapat dilihat pada tabel 1.

Tabel 1. Hasil XRF pasir tiga warna (oksida)

\begin{tabular}{cccc}
\hline $\begin{array}{c}\text { Unsu } \\
\text { r }\end{array}$ & $\begin{array}{c}\text { Komposis } \\
\mathbf{i}(\mathbf{\%})\end{array}$ & $\begin{array}{c}\text { Senyaw } \\
\text { a Oksida }\end{array}$ & $\begin{array}{c}\text { Komposis } \\
\mathbf{i}(\mathbf{\%})\end{array}$ \\
\hline $\mathrm{Al}$ & 6,61 & $\mathrm{Al}_{2} \mathrm{O}_{3}$ & 8,20 \\
$\mathrm{Si}$ & 45,28 & $\mathrm{SiO}_{2}$ & 59,20 \\
$\mathrm{P}$ & 0,94 & $\mathrm{P}_{2} \mathrm{O}_{5}$ & 1,16 \\
$\mathrm{~S}$ & 3,25 & $\mathrm{SO}_{3}$ & 4,32 \\
$\mathrm{Cl}$ & 1,81 & $\mathrm{Cl}$ & 0,95 \\
$\mathrm{~K}$ & 6,42 & $\mathrm{~K} 2$ & 3,94 \\
$\mathrm{Ca}$ & 8,45 & $\mathrm{CaO}$ & 5,79 \\
$\mathrm{Mn}$ & 0,27 & $\mathrm{MnO}$ & 0,16 \\
$\mathrm{Fe}$ & 25,94 & $\mathrm{Fe}_{2} \mathrm{O}_{3}$ & 15,80 \\
$\mathrm{Sr}$ & 0,61 & $\mathrm{SrO}$ & 0,28 \\
$\mathrm{Ba}$ & 0,43 & $\mathrm{BaO}$ & 0,19 \\
\hline
\end{tabular}

Berdasarkan hasil komposisi unsur dapat dikatakan bahwa warna pasir putih dipengaruhi oleh komposisi mineral silikat yang cukup tinggi yaitu $\mathrm{SiO}_{2} \quad 59,20 \%$ dan dipengaruhi oleh mineral $\mathrm{Al}_{2} \mathrm{O}_{3} 8,20 \%, \mathrm{CaO}$ $5,79 \%$ yang memberi pengaruh pada dominasi warna putih pasir tiga warna. Warna hitam pada pasir dipengaruhi oleh kandungan $\mathrm{Fe}$ $25,94 \%$ dengan oksida logam hematit $\left(\mathrm{Fe}_{2} \mathrm{O}_{3}\right)$ $15,80 \%$ dan coklat kemerahan dipengaruhi oleh keberadaan sulfur $(3,25 \%)$ dalam bentuk mineral $\mathrm{SO}_{3} 4,32 \%$. Unsur-unsur lainnya merupakan light element seperti $\mathrm{Al}, \mathrm{P}, \mathrm{S}, \mathrm{Cl}, \mathrm{K}$, dan Ba. Unsur Mn dan Sr merupakan unsur transisi dengan persentase yang kecil turut berpengaruh pada pigmen warna pasir tiga warna yang juga berpengaruh terhadap pembentukan warna pada pasir tiga warna.

\section{Analisis X-Ray Diffraction (XRD)}

Analisis fasa kristal pada pasir tiga warna Pantai Puntaru dilakukan menggunakan instrumen XRD dengan radiasi $\mathrm{CuK} \alpha$ pada panjang gelombang $(\lambda)$ 1,54060 Å pada rentang sudut $2 \theta$ antara $0^{\circ}$ sampai $80^{\circ}$. Hasil uji XRD untuk mengetahui kristalinitas fasa pada pasir tiga warna dapat dilihat pada gambar 1 .

Berdasarkan gambar 1, menunjukkan bahwa pasir tiga warna Pantai Puntaru memiliki kandungan silica quartz $\left(\mathrm{SiO}_{2}\right)$ dengan yang ditunjukkan melalui karakteristik puncak utama dengan $2 \theta$ pada daerah $20,72^{\circ} ; 24,34^{\circ}$; $26,54^{\circ}$ dan $42,39^{\circ}$ dengan puncak utama pada daerah $24,34^{\circ}[2,13]$. Pada pasir tiga warna terdapat kandungan $\mathrm{K}_{2} \mathrm{O}$ terlihat pada $2 \theta$ daerah $24,40^{\circ}$ dengan intensitas $50 \%$ dan adanya hematit $\left(\mathrm{Fe}_{2} \mathrm{O}_{3}\right)$ dan magnetit $\left(\mathrm{Fe}_{3} \mathrm{O}_{4}\right)$ pada $2 \theta$ daerah $35^{\circ}$ dengan intensitas $6,72 \%$ serta $\mathrm{Al}_{2} \mathrm{O}_{3}$ pada $2 \theta$ daerah $42,50^{\circ}$ dengan intensitas $15,62 \%[3,6,14,15]$.

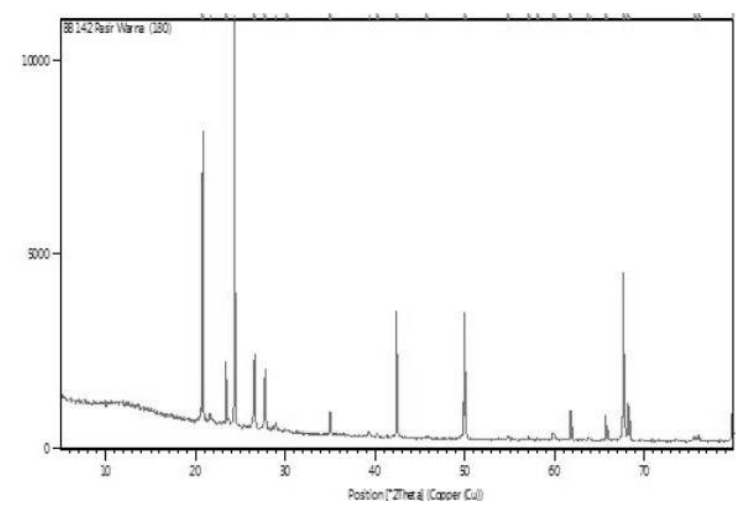

Gambar 1. Difraktogram pasir tiga warna Pantai Puntaru

Analisis Fourier-transform infrared spectroscopy (FTIR)

Penentuan gugus fungsi suatu senyawa dapat diketahui peak yang muncul pada daerah panjang gelombang tertentu berdasarkan pola serapan vibrasi senyawa tersebut. Untuk mengetahui gugus fungsi pada pasir tiga warna maka dilakukan pengujian FTIR dan hasil uji dapat dilihat pada gambar 2.

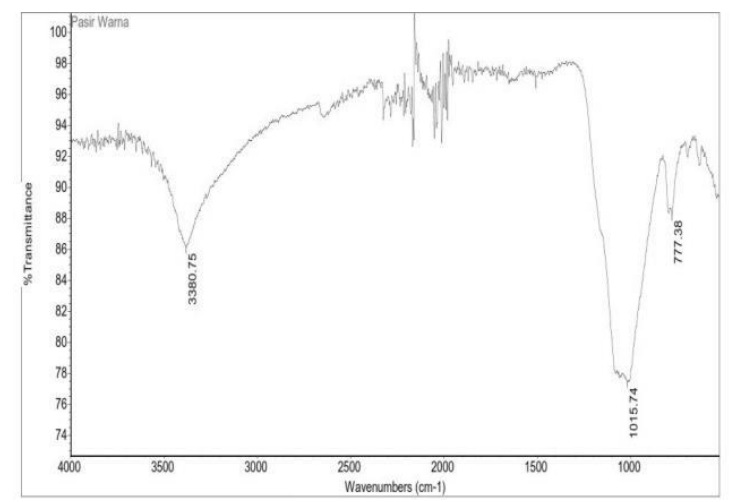

Gambar 2. Spektra FTIR pasir tiga warna Pantai Puntaru

Hasil analisis spektra FTIR pada gambar 2 menunjukkan bahwa daerah pada bilangan gelombang $3380 \mathrm{~cm}^{-1}$ merupakan vibrasi gugus $\mathrm{O}-\mathrm{H}$ dari $\mathrm{Si}-\mathrm{OH}$ yang tumpang tindih dengan vibrasi gugus $\mathrm{O}-\mathrm{H}$ dari $\mathrm{Fe}-\mathrm{OH}$ mengindikasikan bahwa pada pasir tiga warna terdapat silika oksida dan besi oksida [3]. 
Adanya silika pada pasir tiga warna juga ditunjukkan dengan munculnya serapan pada bilangan gelombang $1015 \mathrm{~cm}^{-1}$ yang merupakan serapan karakteristik untuk vibrasi Si-O (ulur asimetri) [15]. Serapan pada bilangan gelombang $777 \mathrm{~cm}^{-1}$ merupakan vibrasi symmetric stretch ikatan $\mathrm{Si}-\mathrm{O}-\mathrm{Si}$ di dalam $\mathrm{SiO}_{2}$.

\section{Ucapan terimakasih}

Ucapan terima kasih kepada LPPM Universitas Tribuana Kalabahi atas bantuan dana Penelitian Internal Tahun Anggaran 2020 sehingga penelitian dapat berjalan dengan baik.

\section{Kesimpulan}

Karakteristik pasir tiga warna Pantai Puntaru berdasarkan hasil analisis XRF menunjukkan bahwa unsur dengan komposisi dominan adalah Si dengan kadar 45,28\% dan hasil uji XRD membuktikan bahwa terdapat silika kristalin $\left(\mathrm{SiO}_{2}\right)$ fasa quartz. Berdasarkan analisis FTIR membuktikan bahwa terdapat kandungan mineral oksida dari silika dan besi pada pasir tiga warna dengan adanya gugus fungsi $\mathrm{OH}$ yang teridentifikasi sebagai Si$\mathrm{OH} / \mathrm{Fe}-\mathrm{OH}$ dan gugus fungsi Si-O. Warna hitam pada pasir dipengaruhi oleh kandungan $\mathrm{Fe}$ $25,94 \%$ dengan oksida logam hematit $\left(\mathrm{Fe}_{2} \mathrm{O}_{3}\right)$ $15,80 \%$ dan coklat kemerahan dipengaruhi oleh keberadaan sulfur $(3,25 \%)$ dalam bentuk mineral $\mathrm{SO}_{3} 4,32 \%$.

\section{Daftar Pustaka}

1. A.L. Rettob.; M. Karbeka. Pengaruh Konsentrasi Larutan HF pada Proses Preparasi terhadap Kadar Unsur Bahan Magnetik Pasir Besi. Walisongo J. Chem. 2019, 2, 6-9.

2. R. Prasdiantika.; A. Rohman.; N. C. Agustin. Pencucian Material Magnetik Pasir Besi Pantai. Semin. Nas. Edusaintek FMIPA UNIMUS. 2019, 201-212.

3. Z. Jalil.; E.N. Sari.; I.A.B.; dan E. Handoko. Phase Composition and Magnetic Behaviour of Iron Sand from Syiah Kuala Beach Prepared by Mechanical Alloying. Indones. J. Appl. Phys. 2016, 4, 110-114, doi: 10.13057/ijap.v4i01.1180.

4. M. Karbeka. Karakterisasi Sifat Kemagnetan Pasir Besi Pantai Puntaru Kabupaten Alor-NTT. lantanida J. 2020, 8.
5. M. Karbeka.; Nuryono.; Suyanta. Synthesis of Silica Coated on Iron Sand Magnetic Materials Modified with 2Mercaptobenzimidazole through Sol-gel. Moroccan J. Chem. 2020, 8, 44-52, 2020, doi: 10.48317/IMIST.PRSM/morjchemv8i1.19124.

6. Trianasari.; P. Manurung.; P. Karo-karo. Analisis dan Karakterisasi Kandungan Silika $\left(\mathrm{SiO}_{2}\right)$ sebagai Hasil Ekstraksi Batu Apung (Pumice). J. Teor. dan Apl. Fis. 2017, 05, 9-14.

7. S. Susilawati.; D. Aris,; T. Muhammad.; W. Wahyudi.; E.R.Gunawan.; K.Kosim.; A. Fitriani.; dan H. Khair. Identifikasi Kandungan Fe Pada Pasir Besi Alam Di Kota Mataram. J. Pendidik. Fis. dan Teknol. 2018, 4, 105-110, doi: 10.29303/jpft.v4i1.571.

8. Alimin.; Maryono.; S. E. Putri. Analisis Kandungan Mineral Pasir Pantai Losari Kota Makassar Menggunakan XRF dan XRD," J. Chem. 2013, 17, 19-23.

9. N.A. Metungku.; D. Darwis.; dan E. Sesa. Pemurniaan dan Karakterisasi Senyawa $\mathrm{SiO}_{2}$ berbasis Pasir Kuarsa dari Desa Pendolo Kecamatan Pamona Selatan Kabupaten Poso. Gravitasi. 2017, 16, 39-43.

10. E. Haryati.; K. Dahlan. Potential of Iron Sand from Betaf Beach, Sarmi Regency and River Sand from Doyo, Jayapura Regency, Papua as Basic Materials of Mortar as Nuclear Radiation Shielding. J. Phys. Conf. Ser. 2018, 997, 1-5, doi: 10.1088/17426596/997/1/012043.

11. M. Karbeka.; Nuryono.; dan Suyanta. Coating of Mercapto Modified Silica on Iron Sand Magnetic Material for $\mathrm{Au}(\mathrm{III})$ Adsorption In Aqueous Solution. IOP Conf. Ser. Mater. Sci. Eng. 2020, 823, 0-8, doi: 10.1088/1757-899X/823/1/012031.

12. F. A. Khalamudilah.; D. Suhendar.; A. Supriadin. Sintesis dan Karakterisasi Pigmen Merah Besi (III) Oksida. al-Kimiya. 2017, 4, 45-50.

13. Bilalodin.; Sunardi.; M. Effendy. Analisis Kandungan Senyawa Kimia dan Uji Sifat Magnetik Pasir Besi Pantai Ambal. J. Fis. Indones. 2013. XVII, 29-31.

14. V. A. Tiwow.; M. Arsyad.; P. Palloan.; M.J. Rampe. Analysis of Mineral Content of Iron Sand Deposit in Bontokanang Village 
and Tanjung Bayang Beach, South Sulawesi, Indonesia. J. Phys. Conf. Ser. 2018, 997, 1-7, doi: 10.1088/17426596/997/1/012010.

15. N. M. Rosiati.; D. Miswanda.; M. Muflikhah. Pelapisan Bahan Magnetik Pasir Besi Bugel Dengan Sitrat. Walisongo J. Chem. 2019, 2, 1-5, doi: 10.21580/wjc.v3i1.3577.

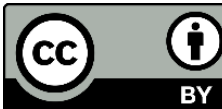

(C) 2021 by the authors. Licensee Fullerene Journal Of Chem. This article is an open access article distributed under the terms and conditions of the Creative Commons Attribution (CC BY) license

(http://creativecommons.org/licenses/by/4.0/). 